\title{
The Moderating Effect of Organizational Climate on the Relationship Between Performance Management Initiatives and Service Delivery in State Corporations in Kenya
}

\author{
Damaris Monari \\ School of Business, Technical University of Mombasa, Mombasa, Kenya
}

\section{Email address:}

dgmonari@gmail.com

\section{To cite this article:}

Damaris Monari. The Moderating Effect of Organizational Climate on the Relationship Between Performance Management Initiatives and Service Delivery in State Corporations in Kenya. European Business \& Management. Vol. 7, No. 2, 2021, pp. 42-55.

doi: $10.11648 /$ j.ebm.20210702.12

Received: June 17, 2020; Accepted: June 30, 2020; Published: May 14, 2021

\begin{abstract}
A positive organisational climate is a precursor for employee commitment and performance in organizations. Efficient service delivery necessitates that state corporations in Kenya establish performance management initiatives that can enhance performance levels. They should also manage the organisation climate in order to keep employee perceptions and attitudes positive. Critique of existing literature on the use of performance management initiatives reveals that gaps exist on the extent which the organisation climate moderates the relationship between performance management initiatives and service delivery. The study, therefore sought to establish the moderating effect of organisational climate on the relationship between performance management initiatives and service delivery in state corporations in Kenya. The study applied descriptive survey research design to gather data from the sampled respondents of the state corporations. Stratified random sampling was used to select respondents from State Corporations to participate in the study. Data analysis was done using both descriptive and inferential statistics with the aid of an analysis tool; statistical package for social Sciences. The study established that performance management initiatives have a positive and significant influence on service delivery among state corporations in Kenya. The organisational climate was found to have no moderating effect on the relationship between performance management initiatives and service delivery. However, based on previous findings, the study recommends that state corporations in Kenya adopt a positive organisational climate that is supportive of performance management as it can improve service delivery.
\end{abstract}

Keywords: Performance Management Initiatives, Organisational Climate, Service Delivery, State Corporations

\section{Introduction}

The key reform in state corporations has been the introduction of performance management practices but only few countries have successfully implemented the same and got positive results. Performance management initiatives were put in place to tackle issues of concern in regard to organisational performance [1]. Majority of countries are seeking to develop a culture in the public sector that is more performance oriented, one that gives much focus to efficiency, effectiveness, quality customer care, an increased focus on results and more decentralised management [2].

In the last two decades, performance management in the public sector has shifted its focus to putting in place processes for measuring outputs and rewarding results [3]. Performance management initiatives should be key elements seen as an enabling means towards getting results from individual employees, teams and the organisation as a whole [4]. This should be done within a framework of setting targets and developing standards which can be measured to establish the performance levels. It also serves as a way in which state corporations can gauge performance to establish whether they are delivering the appropriate services as stipulated by its mission and objectives [5]. Service delivery is a deliberate obligatory decision by the elected or appointed officials to serve or deliver goods and services to the recipients in this case the citizens.

Service delivery framework is a set of principles, standards, policies and constraints used to guide the design, development, deployment, operation and retirement of services delivered by 
a service provider with a view to offering a consistent service experience to a specific user community in a specific business context. Service delivery framework is the context in which a service provider's capabilities are arranged into services [6]. Performance Management initiatives are used to enhance employee's productivity and therefore service delivery through managing their performance [7].

The need to enhance productivity and performance among Kenyan State Corporations has seen the implementation of performance management practices but little consideration appears to have been given to their efficiency in enhancing service delivery. It is important for performance management to be dynamic, so that performance measures remain relevant and continue to reflect the issues of importance to the business [8]. The role of public sector organisations in Kenya is varied, however a common task is that they have a general responsibility of providing services in the geographical areas within which they operate. A basic requirement is that they provide value for money in terms of economy, efficiency and effectiveness [9]. Apart from the economic factors for quantity performance, social accountability is a considerable factor for public institutions and to fulfil this obligation, they have to establish and sustain effective service delivery. Moreover public institutions have to compare well with other public entities and the private sector as well. Therefore, relevant Performance management initiatives have to be developed to ensure the achievement of this objective.

\subsection{Performance Management Initiatives}

A performance management initiative is a human resource intervention which seeks to improve quality and outcomes in organisations. It incorporates the approaches used to improve staff performance and improve service quality [10]. Some of the well-known performance management approaches include; Quality Assurance, Quality Audits, Total Quality Management, Quality Circles, Benchmarking, performance appraisal amongst others. These initiatives share tools that are geared at ensuring quality such as use/customer satisfaction surveys, personal development plans among others [11].

Many contemporary organizations are placing greater emphasis on their performance management initiatives as a means of generating higher levels of job performance [12]. Performance management initiatives, along with other human resource management programs, directly impact key organizational outcomes such as financial performance, productivity, product or service quality, customer satisfaction, and employee job satisfaction. This prompts for adaptable performance management initiatives that are rooted to strategic goals and can guide these organizations to aim for favourable results in their success indicators [13]. The use of performance management initiatives has been acclaimed as an effective and promising means of enhancing service delivery for public enterprises as well as government departments. A performance management system between the organization and employees establishes the general goals for the agency, sets targets for measuring performance and provides incentives for achieving these targets [14].
Effective performance management initiatives should be those that are sensitive to changes in the internal and external environment of the organisation. This therefore calls for review, refocusing and reprioritising internal objectives when the changes are significant enough and redefining the internal objectives and priorities to critical parts of the organisation to ensure alignment of both at all times. It is also important to ensure that the gains achieved through improvement programmes are maintained [15]. An effective performance management means one that articulates organization's vision, establishes key results, objectives and measures at key business unit level [16]. It monitors and controls four key performance measures namely quality, delivery, cycle time and waste. It should also be able to manage the continuous improvement of performance in those key areas [17].

\subsection{State Corporations in Kenya}

A state corporation is a legal entity created by a government to undertake activities on behalf of an owner government. Their legal status varies from being a part of government into stock companies with a state as a regular stockholder. The defining characteristics are that they have a distinct legal form and they are established to operate in commercial affairs [18]. In Kenya, there is a wide range of state corporations and related agencies and learning institutions. Some of them include: Kenya Ports Authority, Kenya Airports Authority, public universities, National Cereals and Produce Board, Kenya Posts and Telecommunications, Kenya Seed Agency among others [19].

The role of State Corporations in the national development effort include promoting or accelerating economic growth and development, building the capability and technical capacity of the state in facilitating and/or promoting national development, important instruments in improving the delivery of public services, creation of good and widespread employment opportunities in various jurisdictions and judicious building of international partnerships [18].

Before the new constitution, there were 262 state corporations in Kenya. In line with vision 2030 and envisioning a future where economic growth and efficiency are maximised, a commission was set up to review the roles of state corporations and make recommendations. The commission recommended a reduction of these corporations to 187 in number. The sate corporations were further reclassified while others were merged or dropped. The main aim for this according to the report was to enhance service delivery. This is owing to the fact that poor performance has been previously reported in State Corporations and this has affected the nation and the quality of lives of citizens is declining. Poverty, hunger, diseases, ignorance, social injustices and economic welfare have all become a major challenge and public trust in government by the citizens is slowly deteriorating. Some of the noted causes of poor performance in state corporations range from excessive controls, multiplicity of principals with multiple and sometimes conflicting objectives, poor management as well as outright mismanagement [18]. 
Performance contracting was introduced in Kenya essentially as a strategy to reorient the management of public sector from focusing on processes, procedures and activities to focusing on results. This would in turn enable reengineering of operations to match the growing need of public demand for better services and therefore restore trust in government and dignity of public service [18].

\subsection{Statement of the Problem}

The need for efficient and effective service delivery has increased over the last decade and the successful implementation and use of performance management initiatives has become of paramount importance in enabling organisations to enhance performance and therefore service delivery. Performance contracting, as a performance management initiative, was introduced in state corporations as a strategy to tackle some of performance problems reported in different government establishments, some of which are, inadequate planning, poor management of projects, wastage of resources, inconsideration of public needs and poor service delivery [18].

Whereas service delivery will always happen with the expectation for responsiveness, responsibility and accountability placed upon public servants, the question of the effectiveness and efficiency with which these services are rendered and whether the clients get best value for their money arises. An exploratory survey on Kenyan service delivery and government interaction indicates that majority of the respondents had negative comments about service delivery by state corporations in Kenya [20]. They cited that $45 \%$ of the respondents had complaints in relation to efficient service delivery and customer care. This is especially concerning infrastructure development, water, electricity, and provision of healthcare and education services. The study further indicates that the respondents on the whole had more negative experiences than positive experiences in relation to service delivery and customer care in Kenya. This shows that there is room for improvement in Kenyan service delivery.

State corporations are expected to continuously find measures that can enable them to raise standards of services delivered to ensure client satisfaction. A number of studies relating to performance management in state corporations have been done, for instance one investigated the factors affecting performance management in local authorities in Kenya [21]. The study focused on how leadership, stakeholder involvement and organisational culture affect performance management but failed to establish whether organisational climate moderates the relationship between the organisational factors performance.

Another study was done on the implementation of performance contracting in state corporations in Kenya where the researchers evaluated how the implementation process can be managed through employee training and development [21]. They failed to relate performance contracting to service delivery by state corporations. Furthermore, a related study was carried out on the effect of performance contracting on service delivery of state corporations in Kenya focusing on the coffee board of Kenya [23]. This study was mainly a case study and therefore this makes it important to develop this study further by looking at all state corporations in Kenya. He also failed to evaluate the moderating effect of organisational climate on service delivery in state corporations.

Despite the numerous studies on performance management, the aspect of whether organisational climate affects the outcomes of service delivery has been largely neglected. This study, therefore, intended to bridge this knowledge gap and sought to determine whether organisational climate moderates the relationship between performance management initiatives and service delivery with reference to state corporations in Kenya.

\subsection{Objective of the Study}

\subsubsection{General Objective}

The study was guided by the following objective.

i. To establish the moderating effect of organizational climate on the relationship between performance management initiatives and service delivery in state corporations in Kenya.

\subsubsection{Research Hypothesis}

Ho5: Organizational climate has no moderating effect on the relationship between performance management initiatives and service delivery in state corporations in Kenya.

\subsection{Theoretical Review}

Theoretical frameworks are explanations about the phenomenon. A theoretical framework provides the researcher the lens to view the world. The study was grounded on two main theories namely: principal-agent theory and expectancy theory.

\subsubsection{The Principal-Agent Theory}

The basic concept of principal-agent theory comes from the relationship between one party (the principal) and another (the agent). Principal-Agent theory is based in the business management area but can be applied also to the social sector [24]. Principal agent theory was developed from organisational management which is derived from economics in terms of links between pay and performance [25]. In this theory, the basic starting point is the situation where one actor (the principal) has an incentive to delegate power to another actor (the agent) with the expectation that subsequently the latter will act in a way which is consistent with the initial preferences of the former [26]. The starting point of the theory corresponds to an assumption that the authority of superior organisations (the principal) is decentralised to subordinate organisations with expectations that agents will use their specialised information and capacities, and thus maximise the principal's benefits [27].

The principal-agent theory can be applied in the public sector to demonstrate the relationship between principals and agents [24, 28]. More specifically, the main idea of this theory is the interacting relationship between organisations, called principals and agents, with regard to several assumptions [24, 
26, 29]. Firstly, the basic assumption of principal-agent theory is that the principal has less information than the agent.

This may cause problems or concern and the principal cannot exactly observe the agent's behaviour. Second, the principal's main interest conflicts with the agent's because each prefers maximising their own benefits [24]. There may also be information asymmetries between the principal and the agent. In reference to this research, the problem of information asymmetries can be reduced by putting in place effective feedback mechanisms that can facilitate efficient communication flows. In response to these problems, [30] suggested that principals may make a contract with agents to share the risk of moral hazard and adverse selection this is because agents also attempt to maximise their benefits, have a propensity to shirk and to deliver only the minimum level of their duties.

A contract may reduce the risk of conflict between principal and agent. The solution to the agent problem is to develop an incentive system under which the principal motivates the agent to achieve the principal's goals [31]. Performance contracts and plans spell out expectations on performance on both the principals and agents in state corporations. Ultimately, in line with theory and in the objective of this study, state corporations are seen to be responsible in delivery of public services by both the public and the government as well and it is assumed that government has unfettered monopoly in public service delivery because of the impact of performance management. Performance measurement may offer, in part, a solution to the principal-agent problem in public sector [32]. Performance measurement refers to control that is divided into two categories: 'after-the-fact' and 'before-the-fact'. The former is government action according to the results of the agent's actions. The latter is prior government action, in the form of policy, instructions, or guidance to the agent.

In terms of the principal-agent theory, the principal can control the agent in the light of the agent's performance, and can request or require more information from the agent if there is a problem of information asymmetry. The principal can guide the agent 'before-the-fact', through regulation, guidelines, and performance indicators, which can be set to require whatever level of performance the principal requires.

In relation to rewards and recognition programs and performance appraisal as variables in this study, the Principal-agent theory recognises that incentives are an important tool for agents, and performance measurement is a useful means of controlling behaviour, which is why performance management in state corporations should focus on performance measurement. Through examining the contextual elements between principal-agent theory and performance measurement, it can be seen there are inherent linkages between them.

For example, the principal would need not only to create effective indicators to measure the performance of the agent but also to play a greater role in the process of service delivery from input to outcome. The principal would also need to confidently represent the concepts of responsibility, accountability and trust and be clear about the importance of these concepts in the performance measurement systems. Accountability is associated with satisfaction with public services and keeping promises in the public sector [33]. The role of trust within public sector organisations has long been important to meeting and maintaining their visible or invisible contract [34].

Thus, trust can be seen both from an individual, and from internal and external organisational environment perspectives. It is associated with individual behaviour and organisational functions, and is a key factor in improving performance in public management. Based on the importance of building trust, there are some key factors to increase the level of trust among all state corporations. Firstly, participation in decision making is regarded as a key to building trust in state corporations. It is strongly associated with democracy.

In terms of the internal relationship of public organisations, the bureaucracy works as a closed model, in which the employee is treated as a resource. On the other hand, participation in the decision making process is said to give rise to significant positive benefits. Employees are able to reach a higher level of performance when supervisors encourage the participation of subordinates. Participative management develops a positive organisational climate since it builds a positive perception to leadership, which in turn has positive effects on performance, productivity, and employee satisfaction. It also fulfils the three basic human needs: increased autonomy, increased meaningfulness, decreased isolation and self-fulfilment. Secondly, empowerment is associated with organisational climate [37, 38]. Empowerment fosters trust, and helps to improve organisational productivity.

State Corporations need to combine the sharing of information on performance with collaborative participation in making decisions. Sharing information is a significant dimension in organisation effectiveness. It helps to integrate inter-organisational processes. A performance appraisal system can help to create the right approach in public service delivery through relating evaluated performance which encompasses comparing goals to plans [39]. Generally, it is recognised that trust can have positive impacts on performance and organisational climate. It can reduce transaction costs through helping to create an effective performance strategy $[40,42]$.

\subsubsection{Expectancy Theory}

The expectancy theory has three main motivational forces i.e. valence, instrumentality and expectancy [43]. Valence means the value and therefore attractiveness of the outcomes. Instrumentality on the hand refers to the degree to which the improvement in job performance is expected to lead to the desired outcomes. It is the belief that when we do things in a certain manner they will lead to the desired ends. Finally, expectancy means the extent to which an increase in effort leads to an increase in job results. Whenever an individual chooses between alternatives which involve uncertain outcomes, it seems clear that his behaviour is affected not only by his preferences among these outcomes but also by the degree to which he believes these outcomes to be possible [43]. Expectancy is 
defined as a momentary belief concerning the likelihood that a particular act will be followed by a particular outcome. Expectancies can be described in terms of their strength. Maximal strength is indicated by subjective certainty that the act will be followed by the outcome, while minimal (or zero) strength is indicated by subjective certainty that the act will not be followed by the outcome.

\subsection{Conceptual Framework}

A conceptual framework is a virtual or written product that explains, either graphically or in narrative form, the main things to be studied which includes, the key factors, concepts, or variables and the presumed relationships among them [44]. The conceptual framework for this study consisted of performance management initiatives as independent variable, Organisational climate as the moderating variable and service delivery as the dependent variable.

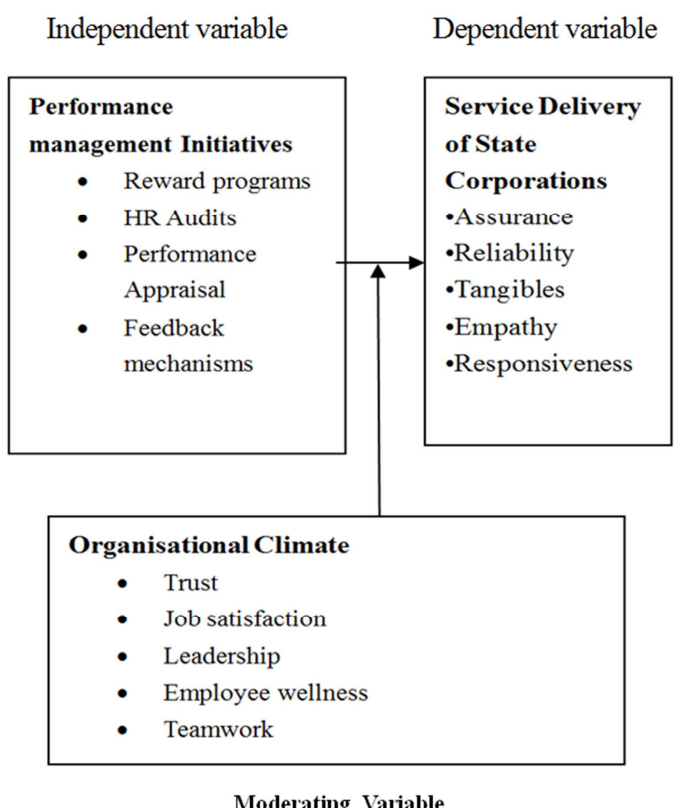

Figure 1. Conceptual Framework.

\subsubsection{Performance Management Initiatives}

Performance management initiatives entail the practices that are established within an organisation to direct results towards what is valued. What an organisation values strongly will be a drive to the employees' behaviour towards those values [45]. This calls for managers to build an effective \& value based organisation that will enable their success in achieving their objectives. If quality of products, quality improvement or quality of service is rewarded then the employees will always think of the quality that they deliver and this may lead them to devise better ways of doing their job [46].

If customer satisfaction and intimacy is rewarded then employees will strive to mould their behaviours towards building good relationships with customers and so that they are able to understand and satisfy their needs [46]. Rewards demonstrate to employees that their behavior is appropriate and should be repeated. Different scholars have spoken strongly on the use of team incentives and they posit that for reliance on teams to manage their work, organizations must develop incentive plans that encourage teamwork and focus team members' attention on performance [47].

State corporations need to design rewards programs that can be motivational to both employees and managers alike and for this, reward and recognition programmes need to be timely, market driven, appropriate and effective. Research and experience in the field of success reinforces the fact that effective and timely recognition can build morale and improve productivity of employees [48]. Studies on motivation demonstrate that there is a positive correlation between the fairness of the reward, the amount of information exchanged between employees and managers, and the workers performance [49]. Motivated employees are very productive and hence help to improve performance [50].

The HR audit is a Human Resource effectiveness too that is concerned with the examination of the HR policies, procedures and practices of the organisation [51]. It is in place to measure to effectiveness and efficiency of Human Resource management. It is an important tool in improving the performance of Human resource management in terms of compliance, service delivery, enabling innovation and development as well as the financial performance.

It focuses on matters such as how well the HR department presents the purpose and supports the strategy of the organisation [52]. It also looks at how well the structures support the organisation and how well the staffing policies of the department support the realization of the organisations strategic intentions. The extent to which the established Human resource functions support the performance of the organisation is very important. Through the HR audits areas of weakness and strength can be identified and this prompts for adjustments for improvements where necessary. A well executed HR audit should capture five different components namely: Functional audit, service audit, compliance audit, financial management audit and lastly a strategic audit which Each aims at evaluating the overall people management strategy with the aim of increasing the value of employees to the business [53]. The strategic audit will examine whether the HR strategy, policies and processes are aligned with and support the achievement of the business's mission and objectives. State corporations need to audit the performance management systems to understand their status.

In line with this research, HR audits should be done with the aim of finding out the extent to which the present system is rational and establishing if the performance initiatives have coherence among them, are aligned with the objectives and are in compliance with the set policy and procedural guidelines. Most importantly an assessment of the overall performance of the HR department within state corporations as an enabling function towards achievement of the major organisational goals should also be periodically examined to provide insight into the level of performance of the function as well the strengths and weaknesses so that continuous improvement can be sought. 
Performance appraisal (PA) assesses the performance against pre-determined measures of performance, based on key success factors which may include measures of deviation from the norm, tracking past achievements and measures of output and input [54]. In contrast to performance management, performance appraisal is a form of employee evaluation [55]. Performance appraisal is a critical tool used by managers in assessment of the performance of employees [56].

This enables organisations to have the ability to achieve competitive advantage through efficient performance of their employees [57]. It therefore becomes an established administrative convention that there should be an avenue by which performance should be measured, monitored and controlled [58].

In the case of service delivery by state corporations in Kenya, the evaluation of employee performance should focus on measuring aspects of performance that can lead to enhanced service standards and in that way the state corporations can utilize performance appraisal to ensure service standards are adhered to and upheld by employees. The service charter for example can serve as a guide to the expected service standards and evaluation of employee performance can be based on how well they adhere to the service delivery standards in the service delivery charters of the respective state corporations they work for.

Primary stakeholders within state corporations are those who may be directly affected by or directly affect the operations of the state corporations. For purposes of this research the stakeholders identified are the employees, the customers and citizens within which state corporations. Stakeholders should be continuously engaged through formal and informal feedback mechanisms [59]. Such feedback can then be in putting in place measures and strategies that can enhance excellence in performance and service delivery.

Customer feedback can be done through customer surveys, customer visits, complaint systems or by use of customer focus groups [60]. Communication is one of those everyday activities that we can tend to take for granted, like the air we breathe. We don't often have to think about our breathing, it just comes naturally. And like breathing, we communicate all the time, whether we intend to or not. The words we choose the tone of our voice, our facial expressions, all work together often subconsciously to relay messages. When communication breaks down, and the intended message is not what was received, it can become costly in terms of wasted time, productivity, and even morale [61]. This can be particularly challenging for supervisors who must routinely communicate with their employees on issues of performance and conduct. Communication is the thread that bonds the various interdependent parts of the organisation together and without it various organisational activities come to a standstill. When it is effective, it encourages better performance and job satisfaction as it enables people to understand their jobs better and get more involved in them.

\subsubsection{Organisational Climate and Service Delivery}

High-performing organizations have climates with particular measurable characteristics [62]. The organisation climate does make a difference to an organization's performance because it indicates how energizing the work environment is for employees. There is clearly more to an organization's performance than an energized employee or the presence of certain organisational and leadership characteristics. However, productivity also depends on the morale which governs discretionary effort and the willingness to go the extra mile. This is unforthcoming if workers feel insecure [63].

Organisational climate can therefore be considered a key variable in successful organizations. The organisational climate as the surface manifestation of organisational culture that consists of the conscious behaviour, such as the feelings or perceptions and attitudes, that is shared by individuals in an organization at a particular time regarding the fundamental elements of the organization and that can positively or negatively influence the behaviour of organisational members in terms of organisational effectiveness [64].

A supportive work environment is related to employees' performance [63]. A positive environment will result in motivated employees who enjoy their work. It, therefore, comes as no surprise that work climate is an excellent predictor of organisational and employee performance. The differences in organisational climate explains the differences in quality of service across organisations and the extent to which service providers are able to realize high levels of commitment and satisfactions towards their jobs.

Researchers who prefer perceptual measures of organisational climate contend that the perceptions of organisational members should be measured because they provide a more encompassing description of the concept [64]. The concept of organisational climate revolves around perceptions. Climate is the feeling in the air and the atmosphere that employees perceive is created in their organisations due to practices, procedures and rewards [65]. From this definition, it is clear that the individual perceptions of employees in the organisation have an impact on the climate. Even though individuals differ in the way they perceive, analyse and interpret information, the climate present in the organisation is a collective view or perception [66].

Organisational climate being a psychological or perceptual description of individuals it can therefore be termed as the collective perception of employees [63]. The sub-dimensions of organizational climate as support, cohesion, pressure, intrinsic recognition and impartiality. Support addresses the existence of managers supporting employees working in an organization [67]. Cohesion emphasizes the harmony and cooperation in the organization. Pressure expresses the pressure created by heavy workload of workers. Intrinsic recognition emphasizes rewarding and appreciation in the organization.

These dimensions, together with dimensions identified on high-performing organizations across three distinct industries, namely banking, public institutions, and business services form the dimensions from which the dimensions measuring 
organisational climate in this study were developed [68, 69]. In this research, organisational climate is conceptualized as the degree to which individuals perceive their organisational environment facilitating their work. This includes intrinsic perceptions on trust, Job satisfaction, leadership, employee wellness, teamwork and service orientation.

\subsubsection{Service Delivery}

The term service means an act of help or assistance. It can also mean a system that provides something needed by the public [70]. Deliverables are outputs derived from inputs which can be materials, knowledge, ideas and equipment. State corporations perform services needed by the within the corporation, its departments and the general public. The reason for performance of these services can be inform of a request, which is translated by an organisation as a customer need and drives the organisation to initiate core processes to enable timely and efficient delivery of the need. The customer expectations form service standards and these are derived from a consultative process.

The standards must be precise and measurable so that users can gauge precisely whether or not they are receiving what was promised [71]. In this research service standards form the focal of performance management initiatives and therefore when standards are met it becomes an indicator for efficiency and effectiveness of delivery. An understanding of the customer's needs and levels of satisfaction with the services provided is very fundamental to the success of any organisation and customer impact emphasises the role of customers in the performance process [72].

High performance is the ultimate goal but if organisations ignore the interests of their customers then their efforts may be futile. A well performing performance management system may be considered highly by the governments but the citizens may not perceive that as a priority if the system is unable to facilitate delivery of service to their expected levels. Customer-based thinking is a relatively new phenomenon in the public sector. The public sector has traditionally been inclined to think in more administratively or bureaucratically. Yet, determining levels of customer impact is steadily gaining ground.

A diverse collection of local governments now routinely use surveys to establish priorities, get feedback from residents regarding services, and examine community perceptions regarding quality of service indicators [73]. The public sector reform recommendations call to public institutions to step up their game in ensuring improved service delivery. Such calls are to ensure the local demands and needs are met at grass root levels and the government's presence is positively felt at local levels [74]. It is important to link performance management and service delivery. In regard to this research, delivery of service is directly dependent on the effectiveness of the performance management initiatives established within state corporations.

A service delivered is the outcome of actions directed towards making that service available. Public services are rendered through government owned entities within its different machineries comprised of departments and collective units as well as employees. All this have to be managed effectively, efficiently and economically. The level of performance of the collective units in state corporations will determine the ultimate service delivered. Most state corporations are utilizing service charters and feedback mechanisms to gauge their level of customer service delivery to both their internal and external customers. A review of most service delivery charters in state corporations reveals that they comply with the Service Quality (SERVQUAL) model of which proposes five dimensions of perceived service quality: Tangibles; reliability; responsiveness; assurance \& empathy as items reflecting both expectations and service performance [75].

\section{Methodology}

\subsection{Research Design}

The study adopted a descriptive survey research design. A research design is a logical thread which holds together all the crucial aspects of the research together so that they can derive meaning [76]. It is a process through which research questions are asked and answered [77]. Descriptive surveys are done when the researcher intends to establish the relationship of events, processes or entities without interfering with the purpose of reporting the facts as they are. This design was chosen and considered as appropriate for this study since it would be able to give room for exploratory and descriptive data.

This form of data was important in understanding the moderating effect of organisational climate on service delivery in state corporations in Kenya. Descriptive research design involves the measurement of a set of variables as they naturally exist [78]. The advantage of this design is that it captures the situation in its full form by describing a particular scenario as it is [76].

The study adopted both quantitative and qualitative approach. Quantitative approach emphasizes data measurement and analysis in numerical form to give precise description. Quantitative approach places emphasis on methodology, procedure and statistical measures to test hypothesis and make predictions [79]. Qualitative research approach helps in analysing information in a systematic way in order to come to some useful conclusions and recommendations on the social settings and the individuals who portray the characteristics [80].

\subsection{Target Population}

The target population for a survey was the entire set of units for which the survey data are to be used to make inferences [81]. Thus, the target population defines those units for which the findings of the survey are meant to generalize [83]. For this research, the target population was made up of the 170 state corporations in Kenya. According to the presidential taskforce report, the total number of state corporations in Kenya stands at 187. However 17 of them are yet to be enacted and 
developed [18].

These state corporations are further classified into five categories which are; purely commercial state corporations-34, State corporations with strategic functions-19, Executive agencies-52, Independent regulatory agencies-20, and Research institutions, Universities, Tertiary education and Training institutions -45 . The unit of analysis for this research was the state corporations since they are instruments of service delivery for Kenyan citizens while the units of observation will be comprised of the line managers in state corporations in Kenya. The researcher issued questionnaires to the line managers and supervisors from all the sampled state corporations. The selection of this category of employees was justified by the fact that they are the ones responsible for the management of employee performance and service delivery in their respective state corporations.

\subsection{Sampling Frame, Sample Size and Sampling Techniques}

The sampling frame describes the list of all population units from which the sample is [82]. The sampling frame for this study comprised of a list of 170 state corporations as presented by the Presidential Taskforce Report of 2013. According to this report, the state corporations are further classified into five categories namely; purely commercial state corporations, executive agencies, Independent regulatory agencies, and research institutions, universities, tertiary education and training institutions. The main reason for the reclassification of state corporations was to enhance service delivery in the public sector as a major indicator of performance [18].

Determination of Sample size is important since it is not possible to study the whole population due to time cost and personnel. A sample size was drawn from the population using the formula given by [77]:

$$
\mathrm{n}=\frac{Z^{2} p q}{d^{2}}
$$

Where:

$\mathrm{n}=$ the desired sample size (If the target population is greater than 10,000)

$\mathrm{Z}=$ the standard normal deviate at the required confidence level.

$\mathrm{P}=$ the proportion in the target population estimated to have characteristics being measured.

$\mathrm{q}=1-\mathrm{p}$

$\mathrm{d}=$ the level of statistical significance set.

If there is no estimate available of the proportion, the target population is assumed to have the characteristics of interest of which $50 \%$ should be used [77]. The $Z$ statistics is taken as 1.96 and desired accuracy at the 0.5 level. The sample size was therefore:

$$
\mathrm{n}=\frac{1.96^{2} \times 0.50 \times 0.50}{0.05^{2}}=384
$$

If the target population is less than 10,000 , the required sample size will be smaller and is calculated using the formula below (Mugenda \& Mugenda, 2003).

$$
n_{f}=\frac{n}{1+\frac{n-1}{N}}
$$

Where $\mathrm{n}_{\mathrm{f}}=$ the desired sample size (when the population is less than 10,000)

$\mathrm{n}=$ the desired sample size (when the population is more than 10,000)

$\mathrm{N}=$ the estimate of the population size.

Using the formula the sample size will be.

$$
\mathrm{n}_{f}=\frac{384}{1+\frac{384-1}{170}}=118
$$

In order to get equal representation from each stratum, percentage presentation was computed by considering the size of each stratum as a percentage of the total population. The percentages of each stratum were then be multiplied by 118 to get the representative proportionate sample from each stratum.

The study adopted stratified random sampling technique to select a sample of 118 corporations from a population of 170 State Corporation in Kenya. The five functional categories of state corporation as categorized by the Presidential Taskforce Report of 2013 were treated as strata after which simple random sampling was done proportionate to the number of corporations in each stratum. The goal of stratified random sampling was to achieve the desired representation from various sub-groups in the population. The selected state corporations formed $69 \%$ of the entire population this surpassed $30 \%$ of the population. A sample of $30 \%$ is considered representative for a population less 500 [77].

The population was made up of parastatal managers in different ranks which include the CEO, General Manager, Assistant General Manager, Operations Manager, Events External affairs manager, Human Resource manager, Public Relations Manager, CSR Strategy manager, Finance Manager and several other line managers. However, the researcher was interested in line managers since they were the ones responsible for the management of employee performance and service delivery of their respective state corporations. Therefore, one line manager was selected to be the respondent for the study from each of the sampled state corporations.

\subsection{Data Collection Instruments}

Data for this study was collected from primary sources using self-administered questionnaires. Data collection as a means by which information is obtained from the selected subjects of an investigation [83]. Data collection involves consulting both secondary and primary data sources in order to elicit information, facts, evidence, proofs or truths regarding the research problems [84]. A standardised questionnaire, capturing the variables under study was prepared. A questionnaire as a set of questions printed or typed in a definite order on a form or a set of forms [76]. They are a list of research questions asked to respondents and they are designed to extract specific information. The questionnaires 
contained both closed and open ended questions. The closed ended questions were used to limit the respondents to the variables under study while the open ended questions were to enable respondents to freely give their opinions in a more pragmatic way [81].

By use of questionnaires, the researcher was able to gather significant amount of data at a very low cost [82]. The research instrument was divided into seven parts where part $\mathrm{A}$ covered the general information, part B, C, D, E and F covered questions related to performance management initiatives and part $\mathrm{G}$ focused on service delivery in state corporations in Kenya.

\subsubsection{Pilot Study}

To enhance reliability and validity, the questionnaire was pre-tested on eight respondents who were selected using purposive sampling from five state corporations forming the category of those with devolved functions. The category was not part of the target population and this guaranteed that those who participated in the pilot study had no chance of appearing in the actual sample.

In pretesting the instrument, half-split method where four respondents were in the HR management and the other four from the line management level was utilised. This made it possible to get a comparison of views from the two different categories of employees since owing to their experience both were considered to be knowledgeable in the research interest areas. Pilot-testing helps to refine the questionnaire so that respondents have no problem in answering the questions and there will be no problem in recording the data [85]. Cronbach's alpha was used to assess internal consistency and reliability of the questionnaire based on the feedback of the pilot test. The subjects were encouraged to make comments and suggestions concerning instructions, clarity of questions and relevance. This revealed vague questions, deficiencies in the questionnaire and provided an opportunity to analyse the data to see if the methods of analysis were appropriate.

\subsubsection{Reliability of the Questionnaire}

The data from the pilot test was tested using cronbach alpha. Cronbach's alpha was used to determine the internal consistency or average correlation of items in the survey instrument to gauge its reliability to assess and improve upon the reliability of variables derived from summated scales [86]. The selected sample for pretesting were selected from ten respondents from five state corporations in Kenya. Measures were taken to ensure that those who participated in the pilot study did not appear in the final sample.

Data reliability was measured using cronbach's alpha coefficient with ranges between 0 and 1 [87]. The Cronbach alpha values obtained for all the variables was higher than 0.5 . If the Cronbach alpha coefficient value realized is higher than 0.5 , it means that the scales are reliable [88].

\subsubsection{Validity of the Instrument}

The validity of the questionnaire was determined using construct validity method. Construct validity is the degree to which a test measures an intended hypothetical construct [77].
Using a panel of experts familiar with the construct is a way in which this type of validity can be assessed. The experts can examine the items and decide what that specific item is intended to measure [76]. The study used different groups of experts in the field of human resource management and issued them with the questionnaires. The experts were required to assess if the questionnaires could effectively be used in establishing performance management initiatives and their influence of service delivery within state corporations in Kenya. This was inorder to establish content and construct validity. The recommendations from the Human resource experts and the pilot study respondents were used to improve on data collection instruments.

\subsection{Data Collection Procedure}

The questionnaires were delivered to the sampled respondents by the researcher, follow ups were made through calls and visits and the questionnaires were collected upon completion. Permission was sought from the management of the state corporations before data collection. The researcher made use of two research assistants who underwent prior training on administering the questionnaire. To enhance response rate the researcher identified and made use of contact persons in each state corporations.

\subsection{Data Processing and Analysis}

Before processing the responses, data preparation was done on the completed questionnaires by editing, coding, entering and cleaning the data. The raw data collected was organised in a manner that enabled systematic analysis. The data was coded to enable easy quantitative processing. The codes were assigned to each response category for each item in the questionnaire. Once coding was done, the data was then entered into the computer and analysis followed by use of Statistical Package for Social Sciences (SPSS).

Data analysis involves reducing accumulated data into manageable size, developing summaries, looking for patterns and applying statistical techniques such as bar charts, percentages, frequency tables and pie charts [82]. Data collected for this study was analysed using descriptive statistics. The mean, median and standard deviation were used to describe the characteristics of the sample. SPSS was used to quantitatively analyse the data. Inferential data was analysed by use of factor analysis and correlation analysis to determine the strength and direction of the relationship between the independent and independent variables.

The analysis enabled prediction to be made as to how the variable deviates from the normal. Hierarchical models were fitted and hypothesis testing was carried out by use of t-tests. Chi square tests were used to establish the strength of dependence between variables. Scatter plots were used to enable the researcher to meaningfully describe a distribution of scores. These showed if the relationships of the dependent variable and the independent variables were linear [89]. Qualitative data analysis seeks to make statements on how categories or themes of data are related [77]. The study, 
therefore, categorized and analysed qualitative data in themes along the lines of the predetermined research objectives. The data was then be presented in bar charts, pie charts and frequency distribution tables for ease of understanding.

\subsection{Measurement of the Variables}

This study involved measurement of six variables namely: Rewards and recognition, HR audits, performance appraisal, feedback mechanisms, organisational climate and service delivery. The performance management initiatives for this study include; Rewards and recognition, HR audits, performance appraisal and feedback mechanisms. A five point likert scale (5-1) was used for each of the statements corresponding to the various parameters of the performance management initiatives. The moderating variable for this study is the organisational climate whose constructs were developed to evaluate the degree to which individuals perceive their organisational environment facilitating their work. This includes intrinsic perceptions on trust, Job satisfaction, leadership, employee wellness, teamwork and service orientation. A five point likert scale (5-1) was used for each of the statements corresponding to the various dimensions of the existing organisation climate.

The dependent variable for this study which is service delivery was measured by the subjective and objective measures of existence of the service delivery charter. A Likert scale (5-1) was used to collect views on the levels of service delivery relation to the SERVQUAL model which proposes five dimensions of perceived service quality: Tangibles; reliability; responsiveness; assurance \& empathy as items reflecting both expectations and service performance [75].

\subsection{Multiple Regression Analysis Model}

Moderated multiple regression (MMR) was used to test the moderating effect of Organisational climate. MMR analysis was used to compare the moderating effect of the organisational climate by analysing and interpreting the $\mathrm{R}^{2}$ change in the models obtained from the model summaries so as to test the hypothesis that organisational climate moderates the relationship between performance management initiatives and Service Delivery.

The regression model for this study generally assumed the following equation;

$$
\begin{gathered}
\mathrm{Y}=\beta 0+\beta_{1} \mathrm{X}_{1}+\beta_{2} \mathrm{X}_{2}+\beta_{3} \mathrm{X}_{3}+\beta_{4} \mathrm{X}_{4}+\mathrm{BZ}+\beta_{1} \mathrm{X}_{1} \mathrm{Z}+\beta_{2} \mathrm{X}_{2} \mathrm{Z}+ \\
\beta_{3} \mathrm{X}_{3} \mathrm{Z}+\beta_{4} \mathrm{X}_{4} \mathrm{Z}+\varepsilon
\end{gathered}
$$

Where; $Y=$ Service delivery $\beta 0=$ constant $\beta \mathrm{i}$ is the coefficient for Xi $(\mathrm{i}=1,2,3,4)$

$\mathrm{X} 1=$ Reward Programs

X2=HR Audit

$\mathrm{X} 3=$ Performance appraisal

$\mathrm{X} 4=$ Feedback Mechanisms

$\mathrm{Z}=$ Organisational climate (Moderator)

$\varepsilon=$ Error Term

$\mathrm{X}_{\mathrm{i}} \mathrm{Z}=$ =Product term / interaction term of organisational climate with each of the independent variables $\left(\mathrm{X}_{1}, \mathrm{X} 2, \mathrm{X}\right.$, $\mathrm{X} 4)$.

\section{Research Findings}

\subsection{Moderated Effect of Performance Management Initiatives and Service Delivery}

The study sought to determine the moderating effect of organizational climate on the relationship between performance management initiatives and service delivery in state corporations in Kenya. The coefficient of determination for the relationship without moderation was 0.642 and with organizational climate as moderating variable 0.645 representing an $r$ change of 0.004 . The coefficient of determination for the change statistics for the model without adjustment was 0.412 and for moderating variable 0.004 . The $\mathrm{p}$ value for the model without moderating variable was 0.0000 implying that it was significant at $99 \%$ confidence level. However, for the moderated model, the $\mathrm{p}$ value was $0.427>0.05$ indicating that the moderating effect was insignificant. Hence, organizational climate has insignificant moderating effect on the relationship between performance management initiatives and service delivery in state corporations in Kenya. The hypothesis that organizational climate has no moderating effect on the relationship between performance management initiatives and service delivery in state corporations in Kenya was therefore accepted.

\begin{tabular}{|c|c|c|c|c|c|c|c|c|c|}
\hline \multirow{2}{*}{ Model } & \multicolumn{9}{|c|}{ Change Statistics } \\
\hline & $\mathbf{R}$ & $\mathbf{R}^{2}$ & $\mathbf{A} \mathbf{R}^{2}$ & SE & $\mathbf{R}$ & $\mathbf{F}$ & df1 & df 2 & Sig. F \\
\hline 1 & $.642 \mathrm{a}$ & 0.412 & 0.386 & 0.626 & 0.412 & 15.931 & 4 & 91 & 0.000 \\
\hline 2 & $.645 b$ & 0.416 & 0.384 & 0.627 & 0.004 & 0.638 & 1 & 90 & 0.427 \\
\hline
\end{tabular}

Table 1. Model Summary on Moderated Relationship between Performance Management Systems and Service Delivery.

a. Predictors: (Constant), Feedback Mechanisms, Reward Recognition, HR Audit Practices, Performance Appraisal

b. Predictors: (Constant), Feedback Mechanisms, Reward Recognition, HR Audit Practices, Performance Appraisal, Organizational Climate

c. Dependent Variable: Service Delivery

Key: $\mathrm{AR}^{2}$ : Adjusted R Squared, SE: Standard Error

The ANOVA results for the moderated effect of performance management initiatives and service delivery in state corporations in Kenya is presented in Table 2. The $p$ value and $\mathrm{F}$ statistic for the unmoderated effect was 0.000 and
15.931 respectively. The $\mathrm{p}$ value for moderated model was 0.000 with $F$ statistic of 12.822 . Notably, without the moderating variable, the model was still significant further supporting the insignificant effect of organizational climate as 
a moderating variable.

Table 2. ANOVA on the Moderated Relationship between Performance Management Initiatives and Service Delivery.

\begin{tabular}{lllllll}
\hline Model & & Sum of Squares & df & Mean Square & F & Sig. \\
\hline 1 & Regression & 24.989 & 4 & 6.247 & 15.931 & $.000 \mathrm{a}$ \\
& Residual & 35.684 & 91 & 0.392 & & \\
& Total & 60.673 & 95 & & & \\
2 & Regression & 25.24 & 5.048 & & \\
& Residual & 35.433 & 90 & 0.822 & \\
& Total & 60.673 & 95 & & & \\
& Total & & & & \\
\hline
\end{tabular}

a. Predictors: (Constant), Feedback Mechanisms, Reward Recognition, HR Audit Practices, Performance Appraisal

b. Predictors: (Constant), Feedback Mechanisms, Reward Recognition, HR Audit Practices, Performance Appraisal, Organizational Climate

c. Dependent Variable: Service Delivery

The study findings indicated that in unmoderated model, reward and recognition had insignificant effect on service delivery $(\beta=0.024, \quad \mathrm{t}=0.233, \quad \mathrm{p}=0.816)$. Also, feedback mechanisms had insignificant relationship with service delivery $(\beta=0.06, \mathrm{t}=0.626, \mathrm{p}=0.533)$. In the moderated model, reward recognition, feedback mechanisms and organizational climate had insignificant effect on service delivery with $\mathrm{p}$ values of $0.863,0.785$ and 0.427 . The findings confirmed the insignificant effect of organizational climate on service delivery.

Table 3. Model coefficients on Moderated Relationship between Performance Management initiatives and Service Delivery.

\begin{tabular}{|c|c|c|c|c|c|c|}
\hline \multirow{2}{*}{\multicolumn{2}{|c|}{ Model }} & \multicolumn{2}{|c|}{ Unstandardized Coefficients } & \multicolumn{3}{|c|}{ Standardized Coefficients } \\
\hline & & \multirow{2}{*}{$\begin{array}{l}\text { B } \\
0.592\end{array}$} & \multirow{2}{*}{$\begin{array}{l}\text { Std. Error } \\
0.4\end{array}$} & \multirow[t]{2}{*}{ Beta } & \multirow{2}{*}{$\begin{array}{l}\mathbf{t} \\
1.481\end{array}$} & \multirow{2}{*}{$\begin{array}{l}\text { Sig. } \\
0.142\end{array}$} \\
\hline 1 & (Constant) & & & & & \\
\hline \multirow{9}{*}{2} & Reward Recognition & 0.031 & 0.131 & 0.024 & 0.233 & 0.816 \\
\hline & HR Audit Practices & 0.292 & 0.111 & 0.288 & 2.644 & 0.01 \\
\hline & Performance Appraisal & 0.42 & 0.128 & 0.371 & 3.285 & 0.001 \\
\hline & Feedback Mechanisms & 0.056 & 0.089 & 0.06 & 0.626 & 0.533 \\
\hline & (Constant) & 0.564 & 0.402 & & 1.403 & 0.164 \\
\hline & HR Audit Practices & 0.282 & 0.111 & 0.278 & 2.526 & 0.013 \\
\hline & Performance Appraisal & 0.384 & 0.135 & 0.34 & 2.836 & 0.006 \\
\hline & Feedback Mechanisms & 0.026 & 0.097 & 0.028 & 0.274 & 0.785 \\
\hline & Organizational Climate & 0.087 & 0.109 & 0.091 & 0.799 & 0.427 \\
\hline
\end{tabular}

a. Dependent Variable: Service Delivery

\subsection{Discussions}

The study found that organisational climate has no moderating effect on the relationship between performance management initiatives and service delivery. The coefficient of determination for the relationship without organizational climate moderation was 0.642 and with organizational climate as moderating variable 0.645 representing an $r$ change of 0.004. The coefficient of determination for the change statistics for the model without adjustment was 0.412 and for moderating variable 0.004 . The $\mathrm{p}$ value for the model without moderating variable was 0.0000 implying that it was significant at $99 \%$ confidence level. However, for the moderated model, the $p$ value was $0.427>0.05$ indicating that the moderating effect was insignificant. The hypothesis that organizational climate has no moderating effect on the relationship between performance management initiatives and service delivery in state corporations in Kenya was therefore accepted.

These findings were contrary to another study that sought to establish the moderating influence of organisational culture and climate in public universities in Uganda [90]. A moderating influence of organisational culture and climate on performance management practices and managed performance was established and confirmed. It is argued that that a supportive work environment is related to employees' performance and argues that a positive environment will result in motivated employees who enjoy their work [63]. The findings by this study contradicts the expectation that organisational climate is a moderator to the relationship between performance management initiatives and service delivery. However, this is not to mean that organizational climate has no effect on service delivery since a significant positive effect was established from the findings.

\subsection{Conclusions}

From the research findings, it is notable that organisational climate is worth investigating especially in today's dynamic business environment and because of its relationship to valued organisational outcomes. However, the effect it has on organisational outcomes may be complex. This therefore makes it necessary to examine the various types of organisational climates. In this future direction, it is suggested that future research focuses on the interactions the several other types of climates have on service delivery unlike using the global climate construct as applied in this research. In a review of climate literature it is realised that multi climate models should be developed which specific interactive effects on relevant outcome criteria. The different types of climates 
given include; innovative climates, service climates, leadership climates, support climate, justice climate and growth climate [91].

\subsection{Recommendations}

The study recommends that state corporations establish positive organisational climate that can support performance management initiatives and assure enhanced service delivery. State corporations therefore need to adopt a supportive work environment which will result in motivated employees who enjoy their work. The differences in organisational climate explains the differences in quality of service standards across organisations and the extent to which service providers are able to realize high levels of commitment and satisfaction towards their jobs.

\section{Suggestions for Future Research}

Since this research focused on the global construct of organisational climate as a moderating variable for the relationship between performance management initiatives and service delivery. It is suggested that future research be carried out focusing on service climate since this is a type of climate that is focused to the outcome of service delivery. This could help in determining whether service climate moderates the relationship between performance management initiatives and service delivery.

\section{References}

[1] Sharif, A. M. (2002). Benchmarking performance management systems. Benchmarking. An international review, 9 (1), 62-85.

[2] Petrie, M. (2002). Organisational Transformation: The Income Support Experience. Journal of Policy Analysis and Management, 32 (4), 55-62.

[3] Heinrich, J., (2003). Measuring Public Sector Performance and Effectiveness. In The Handbook of Public Administration. Guy, M., \& Jon P. (2008) $\left(9^{\text {th }}\right.$ Ed). London: Sage Publications.

[4] Noe, A., Hollenbeck, R., Gerhart, B., \& Wright, P. (2010). Fundamentals of Human Resource Management. New York: McGraw-Hill/Irwin.

[5] Xavier, A., (2010). Establishing Key Performance Indicators for the Upper Echelons of the Senior Public Service. Commonwealth Innovations, 16 (1), 15-25.

[6] Helmsing, A. H. J. (1995). Local Government Central Finance. An Introduction: New York USA.

[7] Poister, T., \& Streib, G. (2003). Performance measurement in Municipal government: Assessing the state of the practice. Public Administration Review, 59 (4), 325-335.

[8] Lynch, R., \& Cross, K., (1991). Measure Up-The Essential Guide to Measuring Business Performance. London: Mandarin

[9] McTavish, D. (2005). Business and Public Management in the UK 1900-2003. Hampshire: Ashgate.
[10] Karen F., Jiju A., \& Susan, O. (2009). Performance management in the public sector. International Journal of Public Sector Management, 22 (6), 478-498.

[11] Aguinis, H. (2009). An Expanded View of Performance Management. San Francisco: Jossey-Bass.

[12] Gruman, A., \& Saks, M., (2011). Performance management and employee engagement. Human Resource Management Review, 21 (4), 123-136.

[13] Pamela, F. (2012). Performance Management and Compensation as Drivers of Organization Competitiveness: The Philippine Perspective. International Journal of Business and Social Science, 6 (21), 93-97.

[14] Hunter, D., \& Gates, R., (1998). Outsourcing: 'functional', 'fashionable' or 'foolish. Human Resource Management Journal, 45 (6), 133-144.

[15] Bititci, U., Carrie, A., \& McDevitt, L. (1997). Integrated performance measurement systems. International Journal of Operations \& Production Management, 17 (5), 522-524.

[16] Lawson, R., Stratton, W., \& Hatch, T. (2003). The benefits of a scorecard system. CMA Management, 13 (9), 24-26.

[17] Yusuff, R. M. (2004). Manufacturing best practices of the electric and electronics firms in Malaysia: Benchmarking. $A n$ International Journal, 11 (4), 361-374.

[18] Republic of Kenya. (2013). Report of the presidential taskforce on State Corporation Reforms. Nairobi: Government printer.

[19] Njagi, L., \& Malel, J. (2012). Time Management and Job Performance in Selected State corporations in Kenya. Australian Journal of Business and Management Research, 9 (5), 19-29.

[20] Crandal, A., \& Mutuku, 1. (2011). MGovernance: exploratory survey on Kenyan service delivery and government interaction. Retrieved July 2015 http://ict4dem.dsv.su.se/Wp content/Files/ihub_M_Governance_survey_OnKenyan_servic e_Delivery_and_Government_Interaction.pdf.

[21] Nzuve, M., \& Kaimuri, N. (2013). Perceived Factors affecting Performance Management among Local Authorities in Kenya: A Case of the City Council of Nairobi. Journal of Management Research, 22 (3), 59-69.

[22] Wesonga, J. N., Tabitha, s., \& Muya, J. N. (2012). Facing the implementation of Performance Contracts in State Corporations in Kenya. Research Journal in Organizational Psychology \& Educational Studies, 1 (5) 284-289.

[23] Gichovi, N. B. (2013). The effect of performance contracting on service delivery of Kenya Parastatals: A case of the Coffee Board of Kenya. Unpublished Master's thesis: Kenyatta University.

[24] Elgie, R. (2002). The Politics of the European Central Bank: principal-agent theory and the democratic deficit. Journal of European Public Policy, 9 (2), 186-200.

[25] Lewis, P. A. (2006). Principal-Agent models of the Employment Relationship and Performance-Related Pay. In Allington \& McCombie (Eds.). The Cambridge Student Handbook in Economics. Cambridge: Cambridge University press.

[26] Carr, J. B., \& Brower, R. S. (1996). Principal-Agent as an explanation of Non-sanctioned Organisational Behaviours: is the theory useful. Academy of Management Proceedings, 26 (8), 323-327. 
[27] Milgrom, P. (1987). Employment Contracts, Influence Activities and Efficient Organization Design. Journal of Political Economy, 96 (3), 42-60.

[28] Moe, T. (1984). The new economics of organisation. American Journal of Political Science, 28 (4), 739-777.

[29] Ingraham, P. W., \& Joyce, P. G., \& Donahue, A. K. (2003). Government Performance: Why Management Matters. Baltimore: John Hopkins University press.

[30] Holmstom, B., Milgrom, p. (1987). Aggregation and Linearity in the Provision of Intertemporal Incentives. Journal of Economic Behaviour and Organization, 12 (1), 305-27.

[31] Rees, R. (1985). The Theory of Principal and Agent: Part 1. Bulletin of Economic Research, 37 (1), 3-26.

[32] Broadbent, J., \& Laughlin, R. (2009). Performance management systems: a conceptual model. Management Accounting Research, 20 (3), 283-295.

[33] Ruscio, K. P. (1997). Trust in the administrative state [Review of the books: Trustworthy government: Leadership and management strategies for building trust and high performance: Trust: The social virtues and the creation of prosperity: and Trust in organisations: Frontiers of theory and research. Public Administration Review, 57 (4), 454-458.

[34] Kim, S. E. (2005). The role of trust in the modern administrative state: An integrative model. Administration \& Society, 37 (6), 611-635.

[35] Nyhan, R. C. (2000). Changing the Paradigm: Trust and its Role in Public Sector Organisations. The American Review of Public Administration, 30 (3), 87-109.

[36] Denhardt, R. B. (1993) Theories of Public Organisations. (2 ${ }^{\text {nd }}$ Ed). Belmont, CA: Wadsworth.

[37] Bowen, D. E., \& Lawler, E. E. (1992). The empowerment of service workers: What, why, how and when. Sloan Management Review, 19 (6), 31-39.

[38] Navran, F. J. (1992). Empowering employees to excel, Supervisory Management. Academy of Management Executives, 26 (1), 42-56.

[39] Lohman, C., Fortuin, L., \& Wouters, M. (2002). Designing a performance measurement system: a case study. European Journal of Operational Research, 156 (18), 267-86.

[40] Ouchi, W. G. (1981). Theory Z: How American business can meet the Japanese challenge. Boston: Addison-Wesley.

[41] Savage, D. (1982). Trust as a productivity management tool. Training and Development Journal, 2 (3), 54-57.

[42] Peters, T. J., \& Waterman, R. H. (1982). In search of excellence: Lessons from America's best 324 run companies. New York: Harper \& Row.

[43] Vroom, V. (1964). The Motivation to Work. New York: Wiley.

[44] Mathieson, K. (2001). Predicting user intentions: comparing the technology acceptance model with the theory of planned behaviour. Information Systems Research, 2 (3), 173-191.

[45] Gardiner, G., \& Pohlman, R. A. (2000). Value Driven Management, How to Create and Maximize Value Over Time for Organizational Success. NewYork: Amacom.
[46] Mujtaba, B. G. (2006). Cross Cultural Change Management. Florida: Lumina Press.

[47] Dessler, Koch, C. G. (2007). The Science of Success: How Market-Based Management Built the World's Largest Private Company. New York: Wiley Publications.

[48] Koch, C. G. (2007). The Science of Success: How Market-Based Management Built the World's Largest Private Company. New York: Wiley Publications.

[49] Bakker, A., \& Schaufeli, W. (2004). Job demands, job resources, and their relationship with burnout and engagement: a multi-sample study. Journal of Organizational Behavior, 25 (3), 293-298.

[50] William, B. K., \& Kinicki, A. (2008). Management a Practical introduction. London: McGraw-Hill Irwin.

[51] Khaef, E., Ahmad, A., \& Peyman, M., (2010). Human Resources management audit in the cement industry and its role to increase organizational efficiency. Culture Management, 7 (19), 5-36.

[52] Curtice, J. (2004). The HR audit for legal compliance and safe business practices. Employment Relations Today, 31 (2), 55-58.

[53] Bloom, P., Nick, H., \& Van reenen, J. (2006). Management practices, work-life balance, and productivity. Oxford Review of Economic Policy, 22 (4), 68- 85.

[54] Hachney, R., Brant, K. \& Birtwhistle, G. (2006). Sustainable virtual markets. International Journal of Retail \& Distribution Management, 34 (4/5), 354-368.

[55] Cardno, C., \& Piggot-Irvine, E. (1997). Effective performance appraisal - Integrating accountability and development in staff appraisal. Auckland: Longman Press.

[56] Sarros, JC, Cooper, BK, Santora JC (2008). Building a climate for innovation through transformational leadership and organizational culture, Journal of Leadership and Organizational Studies, 15 (2): 145-158.

[57] Armstrong, M. A. (2006). Performance Management: Key Strategies and Practical Guidelines. London: Kogan Page.

[58] Bratton, J., \& Gold, J. (2007). Human Resources Management, Theory and Practice. London: Macmillan.

[59] Bambacas, M., \&Patrickson M. (2009). Assessment of communication skills in manager election. Journal of Management Development, 8 (2), 109-120.

[60] Befort, N., \& Hattrup, k. (2003). Valuing Task and Contextual Performance: Experience, Job Roles, and Rating of the importance of job behaviours, Applied H. R. M research, 8 (1), 17-35.

[61] Cynthia, B. (2001). Strategies for improving individual performance and job satisfaction at meadowvale health, Journal of Management Practice, 2 (3), 63-70.

[62] Watkin, C., \& Hubbard, B. (2003). Leadership motivation and the drivers of share price: The business case for measuring organisational climate. Leadership and Organization Development Journal, 24 (7), 380-386.

[63] Gray, R. (2007). A Climate of Success: Creating the right organizational climate for high performance. Amsterdam. Elsevier. 
[64] Gerber, F. J. (2003). The influence of organisational climate on work motivation. Unpublished MComm dissertation. Pretoria: University of South Africa.

[65] Brown, M., \& Heywood, S., (2005). Performance Appraisal Systems: Determinants and Change. British Journal of Industrial Relations, 43 (4), 659-679.

[66] Dormeyer, S. (2003). The study about the leadership style and the organisational climate at the Swedish Civil Aviation Administration in Malmo-Sturup. Master's dissertation, Institute for Psychology, Lund University, Sweden.

[67] Montes, FJL, Moreno, AR, Fernández, LMM (2004). Assessing the organizational climate and contractual relationship for perceptions of support for innovation, International Journal of Manpower, 25 (2): 167-180.

[68] Wiley, J. W., \& Brooks, S. M. (2000). The high-performance organizational climate. In N. M. Ashkanasy, C. P. M. Wilderom \& M. F. Peterson (Eds.), Handbook of organizational culture and climate. Thousand Oaks, CA: Sage.

[69] Tustin, C. M. (1993). A consensus approach to the measurement of organisational climate. SA Journal of Industrial Psychology, 19 (1), 1-4.

[70] Dictionary, C. E. (2003). Complete and unabridged. NY-HarperCollins Publishers.

[71] VandeWalle, D. (2003). An integrated model of feedback seeking behaviour: Disposition, context, and cognition. Journal of Applied Psychology, 85 (2), 996-1003.

[72] Moynihan, D. P. (2006). Managing for Results in State Government: Evaluating a Decade of Reform. Public Administration Review, 66 (1), 77-89.

[73] O’Neill, J. (2008). A Roadmap to Measuring Performance. Government Finance Review, 24 (3), 91-97.

[74] Esra, N., (2010). The Impact of Strategic Human Resource Management on Organizational Performance. Journal of Naval Science and Engineering 2010, 6 (2), 100-116.

[75] Parasuraman, A., Zeitham, V. and Berry, L. (1988). SERVQUAL: a multiple-item scale for measuring consumer perceptions of service quality. Journal of Retailing, 30 (2), $12-40$.

[76] Hoy, W. \& Adams, C. (2015). Quantitative research in education. London, United Kingdom: Sage.
[77] Mugenda, M., \& Mugenda, A., (2003). Research methods: Quantitative and Qualitative Approaches. Nairobi: Acts Press.

[78] Gravetter, F. G., \& Forzano, R. B. (2011). Research Method for the Behavioural Sciences. $\left(4^{\text {th }}\right.$ Ed). California: Wadworth Cengage Learning.

[79] Berg, B. (2004). Qualitative Research Methods for the Social Sciences. $\left(5^{\text {th }}\right.$ Ed). Boston: Pearson.

[80] Coberta, P. (2003). Social Research: Theory, Methods and Techniques. New Delhi: Sage publication.

[81] Kothari, R. (2008). Research methodology; Methods \& techniques. New Delhi: New Age International Publishers.

[82] Cooper, D. R., \& Schindler, P. S. (2008). Business Research Methods. (10th Ed). New York: Mc Graw Hill.

[83] Creswell, J. (2008). Educational Research Planning, Conducting and Evaluating Quantitative and Qualitative Research. Upper Saddle River, NJ: Pearson.

[84] Babbie, E. R. (2010). The practice of social research. $\left(4^{\text {th }}\right.$ Ed). Belmont, CA: Wadsworth Cengage Learning.

[85] Saunders, M., Lewis, P., \& Thornhill, A. (2007). Research Methods for Business Students. London: Pearson Education Limited.

[86] Cronbach, 1. J. (1951). Estimates of test reliability. Journal of industrial psychology, 34 (1) 485-494.

[87] Sekaran, U. (2003). Research Methods for Business. A Skills Building Approach. New York: John Wiley \& Sons.

[88] Klein, L., \& Ford, G. (2003). Consumer search for information in the digital age: an empirical study of pre-purchase search for automobiles. Journal of Interactive Marketing, 13 (3), 29-49.

[89] Klara, N. (2010). Useful Basics in Statistics. Retrieved January 05, 2015 from http://www.230statisticlecturer.0203ioUpp.

[90] Kagaari, J., (2011). Performance management practices and managed performance: the moderating influence of organisational culture and climate in public universities in Uganda. Measuring Business Excellence, 15 (4), 36-49.

[91] Schminke M, Ambrose ML, Neubaum DO. 2005. The effects of leader moral development on ethical climate and employee attitudes. Organization Behavior and Human Decision Process, 97 (7) $135-51$. 